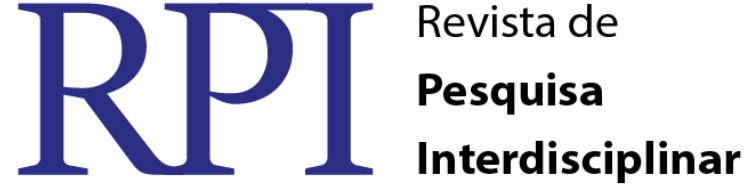

\section{NOVAS TECNOLOGIAS DA INFORMAÇÃO E COMUNICAÇÃO NO ENSINO DE FÍSICA: APRENDENDO A APRENDER COM A PRÁTICA NO ESTÁGIO SUPERVISIONADO}

\author{
Rosa das Neves Pereira - CFP/UFCG \\ Juliano de Sousa Bezerra - CFP/UFCG \\ Gustavo de Alencar Figueiredo - UACEN/CFP/UFCG
}

\begin{abstract}
Resumo
Este trabalho refere-se ao desenvolvimento de atividades pedagógicas na disciplina Estágio Supervisionado III, objetivou utilizar uma metodologia de inserção das Tecnologias Educacionais de Informação e Comunicação (TICs) a fim de possibilitar melhorias no desenvolvimento e aprendizagem de tópicos da Cinemática. Inicialmente investigamos a estrutura em informática da escola e aplicamos um questionário com os/as estudantes com questões sobre o objeto de estudo. No desenvolvimento dos conteúdos foi utilizado alguns dos recursos tecnológicos educacionais, tais como: vídeos, animações, simuladores, aulas em Flash, blog, slides e textos complementares. Além disso, criamos um Ambiente Virtual de Aprendizagem (Blog), a fim de otimizar o tempo da aula, divulgar material extra e atividades extra-classe e propiciar interação virtual. Como resultados, percebemos que com o uso dos recursos de mídia os/as estudantes ficavam mais atentos aos processos que ocorriam na aula, participavam mais das discussões sobre os assuntos e compreenderam melhor os conteúdos, que os/as ajudaram na construção dos novos conhecimentos e desenvolvimentos de habilidades, como melhor interpretação dos modelos científicos. Também verificamos que a escola não possui estrutura que comporte as necessidades formativas objetivadas para implementação da utilização das TICs, como por exemplo a, internet, dificultando, dessa forma, as condições e recursos para o desenvolvimento da proposta de metodologia no Estágio. Outro ponto evidenciado no trabalho foi o tempo destinado pelos/as estudantes nas redes sociais (WhatsApp, Facebook e Instagran) e poucas horas dedicadas aos estudos, o que pode explicar o fato de alguns/as não visitarem frequentemente o Blog criado. Portanto, cientes de que o uso das TICs em sala de aula enfrenta problemas diante da realidade estrutural e organizacional da escola, compreendemos, assim, que não se podem haver mudanças apenas do/a professor/a, mas também na escola como um todo, no papel dos/as estudantes e dos/as gestores/as.
\end{abstract}

Palavras chaves: NTICs, Estágio Supervisionado, Ensino de Física.

\section{NEW TECHNOLOGIES OF INFORMATION AND COMMUNICATION IN PHYSICAL EDUCATION: LEARNING TO LEARN TO PRACTICE IN SUPERVISED}

\begin{abstract}
This study refers to the development of educational activities in the Supervised Internship III discipline, objective to use an insertion methodology of Educational Information and Communication Technologies (ICTs) to enable improvements in the development and learning of topics of kinematics. Initially we investigated the structure of school computer and applied a questionnaire to students with questions about the object of study. The development of content was used some of the educational
\end{abstract}


technology resources, such as videos, animations, simulations, classes in Flash, blog, slides and supplementary texts. In addition, we created a Virtual Learning Environment (Blog) in order to optimize the time of the class, disclose extra material and extra-class activities and provide virtual interaction. As a result, we realized that with the use of media resources students were more aware of the processes taking place in the classroom, participating more in discussions on the issues and understand better the content, which helped in the construction of new knowledge and development of skills, as best interpretation of scientific models. We also found that the school does not have structure incorporating the training needs objectified to implement the use of ICTs, such as, internet, hindering thus the conditions and resources for the development of the proposed methodology in Stage Another point highlighted in the study was the time for the students on social networks (WhatsApp, Facebook and Instagran) and a few hours dedicated to studies, which may explain the fact that some do not often visit the blog created. Therefore, aware that the use of ICT in the classroom facing problems on the structural and organizational reality of school, we understand, so that can not be only the teacher changes, but also in school as a whole, the role of students and managers.

Keywords: ICT, Supervised Training, Physics Teaching.

\section{INTRODUÇÃO}

A realização de estágio supervisionado é uma das exigências da Lei de Diretrizes e Bases da Educação Nacional No 9.394/96, sendo que a Lei № 11.788/08 define os estágios, instituindo novas regras (BRASIL, 1998). No Parecer CNE/CP 28/2001 está claro a obrigatoriedade da realização do Estágio Supervisionado na formação profissional. Objetivando a relação da teoria e a prática social, como informa o Art. $1^{\circ}, \S 2^{\circ}$ da LDB (Lei 9.394/96), tal como expressa sob o conceito de prática no parecer CNE/CP 9/2001, onde defende a ideia de que o planejamento e a execução das práticas no estágio devem estar apoiados nas reflexões desenvolvidas nos cursos de formação. Seguindo estes pressupostos o curso de Física da UFCG/CFP desenvolve seus estágios de maneira que o mesmo possa: oferecer conhecimentos teórico-práticos que ajude na construção do entendimento do processo de ensino e aprendizagem de Física; introduzir o aluno no contexto Escolar do Ensino Médio, para que possa acompanhar criticamente a prática pedagógica do ensino da Física na educação básica; realizar intervenções de observação, planejamento e regência numa turma de Física do Ensino Médio; utilizar uma abordagem metodológica que leve em consideração a inserção das Tecnologias da Informação e Comunicação (TICs); planejar a avaliação da aprendizagem dos/as estudantes da turma acompanhada no estágio; e oferecer conhecimentos teórico-práticos que ajude na construção do entendimento do processo de ensino e aprendizagem de Física.

RPI Revista de Pesquisa Interdisciplinar, Cajazeiras, v. 1, Ed. Especial, 352 - 359, set/dez. de 2016. 
Este trabalho buscou utilizar uma metodológia de inserção das Tecnologias Educacionais de Informação e Comunicação (TICs) a fim de possibilitar uma melhor compreensão do/as estudantes sobre tópicos de Cinemática, com a preocupação de desenvolver capacidades para que eles/as interiorizem os conteúdos e compreendam melhor os fenômenos no mundo à sua volta. $\mathrm{O}$ mesmo se concretizou a partir da disciplina de Estágio Supervisionado III numa turma de $1^{\circ}$ ano, num período de dois meses, com 22 estudantes.

\section{Refletindo Sobre as Tecnologias da Informação e Comunicação na Educação Escolar}

A sociedade atual está cada vez mais equipada com novas tecnologias, ao invés de ficar "parada no tempo" enquanto a sociedade caminha em passos acelerados, exige-se que a escola acompanhe toda essa modernidade. "É preciso visualizar esta situação atual que estamos vivendo. A educação necessita estar atenta às suas propostas e não se marginalizar, tornando-se obsoleta e sem flexibilidade" Tajra (2012, p. 19). De acordo com Toffler, apud (TAJRA 2012, p. 19) estamos vivendo em uma era revolucionária que vai além de computadores e inovações nas telecomunicações, estão ocorrendo mudanças em todas as áreas (economia, social, filosófica, religião, etc.) e isso nos impõe uma nova maneira de viver. Kenski (2007, p. 38) chama de Nova lógica tecnológica onde todas as áreas (economia, entretenimento, comunicações, financeiras, políticas, culturais, educacionais) estão utilizando de forma intensiva as tecnologias digitais, a internet e as TICs, trazendo com isso, novas formas de pensar, aprender, agir, trabalhar, interagir, fazer compras, etc.

Houve primeiramente a tentativa de inclusão das tecnologias na educação, chamada por Tajra (2012, p.38) de Tecnologia Educacional que "está relacionada à prática do ensino baseado nas teorias de comunicações e dos novos aprimoramentos tecnológicos (informática, TV, rádio, vídeo, áudio, impressos)", mas foi desenvolvida com uma visão bastante tecnicista, preocupada especialmente com a utilização dos recursos tecnológicos, sem fazer avaliações de seus impactos na aprendizagem, em parte influenciada pelo capitalismo e o poderio tecnológico sobre a sociedade, onde as pessoas/educandos deveriam aprender a utilizar essas tecnologias principalmente para fins trabalhistas. Tajra (2012)

\section{Percursos Metodológicos No Estágio Supervisionado}

RPI Revista de Pesquisa Interdisciplinar, Cajazeiras, v. 1, Ed. Especial, 352 - 359, set/dez. de 2016. 
A primeira etapa partiu de discussões e orientações com o Orientador do estágio, entendemos a extrema importância da mesma, sendo imprescindível para nossa formação pedagógica e planejamento adequado das intervenções. "Para que as TICs possam trazer alterações no processo educativo, no entanto, elas precisam ser compreendidas e incorporadas pedagogicamente." (KENSKI, 2007; p. 46). Ou seja, não adianta esperar bons resultados somente ao utilizá-las na educação, é preciso fugir do tecnicismo (TAJRA, 2012) e utilizá-las de maneira correta, escolher qual tipo de tecnologia é a mais adequada para determinados objetivos e planejar pedagogicamente sua utilização.

São diversas as formas de utilização das TICs no processo de ensino-aprendizagem, como bem defende Cox (2008, p.35) estão entre elas: as simulações, jogos digitais, programas educacionais e comunicação: onde aqui podem entrar os ambientes virtuais de aprendizagem. $\mathrm{O}$ autor defende a ideia que "a inserção dos computadores nas salas de aula de aula pode favorecer o processo de educação escolar desde que provoque a revisão das posturas dos agentes escolares e o consequente aprimoramento de suas práticas." (COX, 2008; p.54-55).

O conteúdo ministrado durante o estágio foi a Cinemática, partimos desde aspectos Históricos, conceitos básicos sobre o movimento, Movimento Retilíneo Uniforme (MRU) e Movimento Retilíneo Uniformemente Variado (MRUV), até Queda dos corpos. Durante o desenvolvimento dos tópicos utilizamos vários recursos educacionais de informação e comunicação, tais como; vídeos, sites, Blog, simuladores, animação, aulas em Flahs, slides e textos complementares. sendo que em todas as aulas utilizamos apresentação de slides em Datashow. Iniciamos tratando do movimento variado com um vídeo do piloto Fernando Alonso da Fórmula 1, num carro da Ferrari, onde a partir do mesmo discutimos um pouco sobre esta modalidade de competição e questionamos o comportamento da velocidade durante o vídeo, afim de fazer com que o estudante reflita sobre o comportamento da velocidade e perceba a presença e o conceito de aceleração ao ver o vídeo; Também utilizamos o site Inovação Tecnológica para discutir sobre os movimentos uniformes, o conceito de aceleração e sua definição matemática. Os simuladores foram outro recurso bastante utilizado, dentre eles está $O$ homem em movimento, os mesmos possibilitaram simular o MRU e também MRUV, a partir da manipulação do usuário, na escolha dos valores de velocidade e aceleração, também pudemos visualizar os gráficos do movimento, entre outros.

Nossa abordagem metodológica também se baseou, além de outros já elencados, em Moran (2013) que defende a ideia de novos espaços de atuação do professor com as tecnologias, ele destaca quatro espaços: Reorganização dos ambientes presenciais para que RPI Revista de Pesquisa Interdisciplinar, Cajazeiras, v. 1, Ed. Especial, 352 - 359, set/dez. de 2016. 
os/as professores/as reorganizem seu tempo e espaço para atividades propostas fora da sala de aula, onde a aula presencial seria para discussão e troca de ideias ou finalização e orientação pelo professor; Atividades nos ambientes presenciais conectados: a possibilidade de um dia as escolas terem estrutura o suficiente para dispor de rede de internet, onde a sala de aula seria um espaço de pesquisa com todos conectados ao mesmo tempo, mas deixando claro também que nossa realidade está muito distante disso; A utilização de ambientes virtuais de aprendizagem poderia estender o tempo de aula e propiciar comunicação entre professor/a e aluno/a, poderiam interagir online na resolução de atividades em grupo ou individual; e Inserção em ambientes experimentais, profissionais e culturais, onde através da internet os/as estudantes podem ultrapassar fronteiras, podendo fazer visitas virtuais a museus, bibliotecas, etc. (MORAN 2013, p. 27-29).

Então, partindo desse pressuposto, colocamos em prática a criação de Ambiente virtual de Aprendizagem, para isso, optamos pela criação de um Blog, onde os/as estudantes teriam mais um espaço de aprendizagem, que tinha como principais objetivos: otimizar o tempo de sala aula; divulgar material extra a ser estudado e atividades para casa; e propiciar interação virtual entre eles mesmos e com a professora estagiária. Para iniciar, aplicamos um questionário com perguntas sobre as tecnologias, equipamentos digitais, internet, utilização desses recursos pelos/as estudantes, dentre outras.

\section{Resultados E Discussões}

\section{Estrutura e recursos em informática da escola e dos/as estudantes}

Em relação à investigação das condições estruturais e de serviços relacionados à informática na escola, o site da escola afirma que a mesma possui os seguintes itens: acesso à internet, banda larga, laboratório de informática (com 19 computadores), 1 copiadora, 3 equipamentos de som, 3 impressoras, 1 equipamento de multimídia (Datashow), 1 TV e 1 videocassete, porém quando fomos investigar na prática há sérios problemas: entre todos os equipamentos que a escola possui, o professor só tem acesso para utilização em sua prática o Datashow e a TV, sobre os demais ele tem que se virar e pagar por fora; só funcionam 5 dos 19 computadores do laboratório de informática e de forma limitada, logo não dá para desenvolver nenhuma atividade; e não há internet e nem banda larga na escola.

RPI Revista de Pesquisa Interdisciplinar, Cajazeiras, v. 1, Ed. Especial, 352 - 359, set/dez. de 2016. 
Assim, houve uma grande discrepância entre teoria e prática pois escola não apresentava a estrutura necessária para um bom desenvolvimento da metodologia. Então, tivemos muitas das vezes que usar equipamentos e recursos da própria Universidade nas aulas.

A partir das análises do questionário (ver dados em anexo), verificamos que os/as discentes possuem computador ou tablet que todos têm acesso a internet (primeiro gráfico em anexo), logo, a partir das condições de recursos dos/as mesmos/as e das horas que passavam na internet questionário (segundo gráfico em anexo), pudemos chegar à conclusão de que seria viável a utilização do Blog como ambiente virtual. Sendo assim, apesar da escola não oferecer a estrutura desejada, pudemos por em prática estratégias a partir das condições estruturais e de recursos dos/as discentes.

\section{Metodologia de inserção das TICs e dificuldades encontradas}

$\mathrm{Na}$ abordagem Histórica do tema percebemos a importância dos slides já que alguns dos tópicos tratados e imagens não se encontravam no livro didático dos/as estudantes. Durante a utilização dos vários recursos educacionais de informação e comunicação, tais como; vídeos, sites, aulas em Flash, percebemos que nestes momentos em que se utilizavam estes recursos os/as estudantes participavam mais das discussões e a aula tinha altos rendimentos. Um dos recursos que se destacou por facilitar a compreensão dos assuntos abordados foram os simuladores, pois os/as discentes puderam visualizar movimentos difíceis de encontrar no cotidiano e a partir da manipulação dos valores eles/as se sentiram mais atuantes. Os vídeos de aula em Flash e as animações desempenharam um importante papel no entendimento de alguns conteúdos e experimentos que marcaram a construção da Física, tendo em vista o fato da escola não possuir laboratório para realização de experimentos sofisticados.

Enquanto ao Blog Física Interativa - Estágio Supervisionado, reconhecemos as grandes potencialidades do mesmo na prática pedagógica devido ao fato de ter cumprido com dois dos objetivos pelo qual foi criado: contribuirá bastante para divulgação de material a ser estudado como postagens de textos, vídeos, simulações/animações e atividades extraclasses para os estudantes, e consequentemente conseguimos otimizar o tempo das aulas de Física, que além de ser pouco, houve vários dias em que não teve aula devido à questões diversas da RPI Revista de Pesquisa Interdisciplinar, Cajazeiras, v. 1, Ed. Especial, 352 - 359, set/dez. de 2016. 
escola, sendo assim o blog teve o intuito de "ampliar o acesso à informação e para favorecer a criação de ambientes de aprendizado, que enfatizem a construção de conhecimento." (VALENTE, 1999; p. 29). Só não conseguimos alcançar uma interação virtual entre os/as estudantes e com a estagiária, isso devido a problemas burocráticos do Blog, pois o mesmo exigia que os/as visitantes tivessem um e-mail para fazer comentários, diálogos ou perguntas, sendo que os/as discentes não tinham, outros esqueceram senhas e também não criaram.

Um dos problemas com o uso do Blog foi o fato de que nem todos os/as discentes o visitavam frequentemente, apesar de terem todas as condições necessárias para acesso, verificamos isso devido a execução das leituras de alguns textos e postagens do Blog e não cumprimento de atividades e prazos presentes no mesmo, talvez pelo fato de ainda passarem muito tempo acessando redes sociais (tabela I e gráfico III). Uma dificuldade técnica foi encontrada durante sua criação, pois eu nunca havia feito um antes, então para executar esta difícil tarefa tive que pedir ajuda a amigos de cursos relacionados à computação, pois precisou de conhecimentos de Programação e nosso curso não dispõe deste componente nas cadeiras de informática.

Tomamos ainda algumas precauções, como iria trabalhar com um ambiente virtual com adolescentes, houve um cuidado quanto à comentários, diferentemente de uma rede social, para poder comentar as postagens, interagir entre si e também com a professora estagiária, os estudantes precisavam ter uma conta de e-mail ativa, sendo que os comentários tinha um sistema de filtragem e controle, que criamos para evitar possíveis confusões de comentários ou crimes de internet por parte dos visitantes. Porém, não há nada que não possa ser aperfeiçoado numa outra oportunidade.

\section{Considerações Finais}

Estamos cientes de que o uso das TICs em sala de aula enfrenta problemas diante da realidade estrutural e organizacional das escolas, compreendemos assim que não se podem haver mudanças apenas do/a professor/a, mas também mudanças na escola como um todo, no papel dos/as estudantes e dos/as gestores/as. Porém, este trabalho nos mostrou que adaptações às condições das mesmas, como a utilização dos recursos disponíveis e criação de novos ambientes de aprendizagem como os virtuais, produz um efeito positivo se for planejado e adequado a cada situação, afim de "ampliar o acesso à informação e para favorecer a criação 
de ambientes de aprendizado, que enfatizem a construção de conhecimento." (VALENTE, 1999; p. 29)

Após o término do estágio reconhecemos que os recursos tecnológicos como o computador e os serviços de internet oferecem uma vasta riqueza de recursos a serem utilizados tanto em aula, como também em casa pelos estudantes. Claro que o uso TICs não será a salvadora da educação, mas pode ajudar bastante em termos de construção dos novos conhecimentos e desenvolvimentos de habilidades, tais como melhor interpretação dos modelos científicos.

\section{REFERÊNCIAS}

BRASIL, SECRETARIA DO ENSINO FUNDAMENTAL. Parâmetros Curriculares Nacionais: Ciências Naturais $-5^{\mathrm{a}}$ à $8^{\mathrm{a}}$ séries. Brasília: MEC/SEF, 1998.

CARVALHO, Ana Maria Pessoa de. Estágios nos Cursos de Licenciatura. Editora: Cencage Learning, São Paulo-2012.

COX, K. K. Informática na educação escolar. - 2 ed. Campinas, São Paulo: Autores Associados, 2008. - (Coleção polêmicas do nosso tempo, 87).

KENSKI, V. M. Educação e Tecnologias: O novo ritmo da informação. - Campinas, SP: Papirus, 2007.

MORAN, J. Os novos espaços de atuação do professor com as Tecnologias. - Novas Tecnologias e mediação pedagógica - Papirus, $21^{\circ}$ ed. 2013.

PINTO, Álvaro Vieira. O conceito de Tecnologia. Vol I - Rio de Janeiro: Contraponto, 2005 .

TAJRA,S. F. Informática na Educação: Novas ferramentas pedagógicas para o professor na atualidade. 9. Ed. São Paulo: Érica, 2012.

UNIVERSIDADE FEDERAL DE CAMPINA GRANDE. Projeto Pedagógico do curso de Licenciatura em Física. Cajazeiras, 2011.

VALENTE, José Armando (Org.). O computador na sociedade do conhecimento, Campinas, SP:UNICAMP/NIED, 1999. 